\title{
Rhein inhibits malignant phenotypes of human renal cell carcinoma by impacting on MAPK/ NF- $\kappa B$ signaling pathways
}

This article was published in the following Dove Press journal:

OncoTargets and Therapy

\section{Ya-Li Ma* \\ Fang Chen* \\ Jun Shi}

Department of Nephrology, Huaihe Hospital Henan University, Kaifeng,

People's Republic of China

*These authors contributed equally to this work
Correspondence: Jun Shi

Department of Nephrology,

Huaihe Hospital Henan University,

No 8 Baogongbei Road, Gulou District,

Kaifeng City, Henan 475000, People's

Republic of China

$\mathrm{Tel}+8637 \mid 23906900$

Fax +86 37I 23906778

Email sunc5636@163.com
Background: Rhein, an anthraquinone derivative of rhubarb, is traditionally used in Chinese herbal medicine. Now emerging studies suggest its antitumor properties in many human cancers. The present study aims to investigate the antitumor role of Rhein and its possible mechanism in human renal cell carcinoma (RCC).

Materials and methods: Three RCC cell lines (A489, 786-O and ACHN) were used as the cell models. We applied CCK-8, cell counting, colony formation, wound healing and Transwell assays to assess the antitumor roles of Rhein in RCC cells in vitro. The therapeutic efficacy of Rhein was further evaluated by intraperitoneal administrations in tumor formation of mice. Western blot was used to investigate the underlying mechanisms of action of Rhein.

Results: Rhein inhibited RCC cell proliferation in a dose- and time-dependent manner. It also suppressed RCC cell migration and invasion in vitro. Moreover, Rhein was able to inhibit tumor growth in nude mice by intraperitoneal administration in vivo. Mechanistically, the protein levels of phosphorylated MAPK (mitogen-activated protein kinase, extracellular signal-regulated kinase and c-Jun N-terminal kinase), phosphorylated Akt and two targets of NF- $\mathrm{KB}$ (nuclear factor kappa-light-chain enhancer of activated B cells) pathway, matrix metalloproteinase 9 and CCND1 were all markedly reduced by Rhein treatment.

Conclusion: Rhein processed the antitumor effects in RCC cells by inhibiting cell proliferation, migration and invasion, and these tumor-suppressing functions might be mediated by MAPK $\mathrm{NF}-\mathrm{KB}$ signaling pathways.

Keywords: Rhein, renal cell carcinoma, antitumor effects, MAPK, NF-кB

\section{Introduction}

Renal cell carcinoma (RCC) represents the third most frequent urologic malignancy, accounting for approximately over $90 \%$ of all renal cancers in adults. ${ }^{1}$ Accompanied by its increasing incidence and high mortality rate, it threatens human health seriously in the worldwide. ${ }^{2-4}$ Among all the RCCs, more than $70 \%$ belong to the clear cell subtype. ${ }^{5}$ Typical therapies such as chemotherapy, radiation therapy and hormonal therapy have made an improvement on the overall survival of RCC patients. ${ }^{6}$ Most patients initially respond to these drugs; however, drug resistance always occurs and leads to poor prognosis, especially for those metastatic RCCs. ${ }^{7}$ Thus, to identify novel therapeutic agents against RCC is urgently required for effective treatment.

Numerous studies have found that extracts from natural products possess antitumor effects. ${ }^{8,9}$ The application of Chinese herb medicine on treating human diseases further supports the beneficial roles of natural compounds. ${ }^{10}$ Recently, increasing reports show that several Chinese herb medicines can be clinically used to improve the efficiency 
of conventional cancer therapies as well as to reduce the side effects of chemotherapies for human malignancies. ${ }^{11,12}$

Rhein (4,5-dihydroxyanthraquinone-2-carboxylic acid), a primary anthraquinone derivative of rhubarb (about 1.9\% $\mathrm{w} / \mathrm{w}$ ), is traditionally used in Chinese herbal medicine. ${ }^{13,14}$ It has been reported that Rhein treatment could lead to tumorsuppressing phenotypes in various cancers. For instance, it inhibits cell proliferation of human breast, glioma and lung cancer cells, ${ }^{15-17}$ and induces apoptosis of human hepatocellular carcinoma and gastric cancer cells ${ }^{18,19}$ through different mechanisms. Its antitumor effects have also been demonstrated in vivo in rat liver. ${ }^{20}$ To our knowledge, the role of Rhein in RCC cell growth remains largely unknown. The goal of the present study is to address the effects of Rhein on RCC cells and explore the underlying mechanisms to shed light on its potential usage as a candidate RCC therapy agent.

\section{Materials and methods}

All experiments were performed following Huaihe Hospital Henan University and the People's Republic of China guidelines and regulations. The procedures of animal experiments were approved by the Animal Ethics Committee of the Huaihe Hospital Henan University and performed in accordance with the guidelines for the use of experimental animals from the National Institutes of Health.

\section{Cell culture}

Human RCC cell lines A498, 786-O and ACHN used in this study were from the Cell Bank of the Chinese Academy of Sciences. Cells were grown in Dulbecco's Modified Eagle's Medium or 1640 medium (Gibco, Life Technologies) with 10\% fetal bovine serum (FBS; Gibco, Life Technologies), $100 \mathrm{U} / \mathrm{mL}$ penicillin and $100 \mu \mathrm{g} / \mathrm{mL}$ streptomycin at $37^{\circ} \mathrm{C}$ in a humidified incubator containing $5 \% \mathrm{CO}_{2}$.

\section{Western blot}

Cell lysates were harvested from A498 and 786-O cells with or without treatment of different dose of Rhein by RIPA buffer (Beyotime). Protein lysates were dissolved in $2 \times$ loading buffer and boiled for $15 \mathrm{~min}$ at $100^{\circ} \mathrm{C}$. After that protein lysates were resolved on $11 \%$ sodium dodecyl sulfatepolyacrylamide gel electrophoresis gels and transferred to nitrocellulose membrane. Resultant blots were blocked with $5 \%$ skim milk and reacted with properly diluted primary antibodies against glyceraldehyde 3-phosphate dehydrogenase (Santa Cruz), phospho-extracellular signal-regulated kinase (Santa Cruz), total extracellular signal-regulated kinase (Santa Cruz), p-AKT (Cell Signaling Technology),
phospho-c-Jun N-terminal kinase (Cell Signaling Technology), matrix metalloproteinase 9 (MMP9) (Cell Signaling Technology) and CCND1 (Cell Signaling Technology) for $1 \mathrm{~h}$ at room temperature. Immune complexes were detected by horseradish peroxidase-conjugated secondary antibodies, followed by enhanced chemiluminescence reaction (Amersham Pharmacia Biotech).

\section{CCK-8 Assay}

Rhein was purchased from Sigma Chemical Company (St Louis, MO, USA). In vitro antiviability effect of Rhein on A498, 786-O and ACHN cells was examined using CCK-8 assay. Cells were plated in 96 -well plates $\left(1 \times 10^{4}\right.$ cells $)$ in $200 \mu \mathrm{L}$ of full medium each well and then treated with serial dilution of Rhein $(0,10,20,40,80$ and $160 \mu \mathrm{M})$. After treatment for $48 \mathrm{~h}, \mathrm{CCK}-8$ assay was performed using CCK-8 KIT as per the manufacturer's instructions. Absorbance at $490 \mathrm{~nm}$ (OD490) was detected by using a microplate reader.

\section{Cell counting assay}

A498, 786-O and ACHN cells were trypsinized and seeded into 12 -well plates at a density of $2 \times 10^{5}$ cells per well. Eighteen hours later, cells were treated with $60 \mu \mathrm{M}$ Rhein for different time periods $(0,12,24,36$ or 48 h). At each point of time, cells were counted by blood cell counting chamber. Counting experiments were repeated in triplicate independently.

\section{Colony formation assay}

A498 cells $\left(3 \times 10^{3}\right.$ cells/well) were seeded in six-well plates. The cells were treated with different dilutions of Rhein (30 and $60 \mu \mathrm{M}$ ) and cultured for 14 days. Cells were washed with PBS for twice and fixed with 4\% paraformaldehyde. After washing, the plates were air dried, and the colonies were photographed using a microscope. The total number of colonies was counted. The experiments were performed in triplicate.

\section{Wound healing assay}

For the wound healing assay, $1 \times 10^{6}$ A498 or $786-\mathrm{O}$ cells were seeded into six-well plates and cultured until confluent. A P200 pipette tip was used to make a straight line simulation "wound". Then cells were treated with different dilutions of Rhein (30 and $60 \mu \mathrm{M}$ ) for $24 \mathrm{~h}$ (serum-free medium) or $48 \mathrm{~h}$ (5\% FBS medium). After that, cells were washed several times with PBS to remove cell debris. The extent of wound closure was monitored and photographed using a microscope at $48 \mathrm{~h}$. 


\section{Transwell invasion assay}

For the invasion assays, the A498 or 786-O cells were plated in the top chamber with a BD Matrigel-coated membrane. The cells were plated in a serum-free medium with different dilutions of Rhein ( 30 and $60 \mu \mathrm{M})$, and a medium supplemented with $15 \%$ serum was used as a chemoattractant in the bottom chamber. The cells were incubated for 24 or $48 \mathrm{~h}$ at $37^{\circ} \mathrm{C}$ and $5 \% \mathrm{CO}_{2}$ in a culture incubator. After that, the noninvasive cells were removed from the top sides of the Transwell membrane filter inserts. The invaded cells on the bottom sides of the inserts were stained with $0.25 \%$ crystal violet and photographed using a microscope.

\section{Cell cycle analysis}

For determining Rhein on cell cycle progression, A498 cells were grown for $48 \mathrm{~h}$ with $60 \mu \mathrm{M}$ Rhein. Cells were washed with cold PBS and collected by trypsinization. The cells were fixed with $70 \%$ ethanol and treated with RNase $(5 \mathrm{mg} / \mathrm{mL})$ and $50 \mathrm{mM}$ propidium iodide (Sigma-Aldrich) for $30 \mathrm{~min}$. After staining, the cells were subjected to flow cytometric analysis with BD FACSVerse ${ }^{\mathrm{TM}}$ (BD Biosciences).

\section{Single-cell gel electrophoresis assay (SCGE)}

DNA damage (single-strand breaks) was measured by SCGE, also known as comet assay. SCGE assays were performed according to the method reported previously ${ }^{21}$ by using A498 cells treated with $60 \mu \mathrm{M}$ Rhein for $48 \mathrm{~h}$. The photographs were visualized under a fluorescence microscope (Olympus, Tokyo, Japan). Apoptotic cells characterized by shrunken nuclei and comet tails stretching were counted.

\section{Xenograft tumor mouse model}

In the tumor growth experiment, 786-O cells were subcutaneously injected into BALB/c nude mice $\left(5 \times 10^{6}\right.$ cells per mouse, $\mathrm{n}=18$ ). Seven days later, 18 mice were divided randomly into three groups, followed by treating with PBS (control group), $75 \mathrm{mg} / \mathrm{kg}$ Rhein (low dose group) or $150 \mathrm{mg} / \mathrm{kg}$ Rhein (high dose group) every 2 days. The tumor sizes were measured by vernier caliper every week and calculated using the formula $\mathrm{V}=\left(\mathrm{L} \times \mathrm{W}^{2}\right) \pi / 6\left(\mathrm{~V}\right.$ : volume $\left[\mathrm{mm}^{3}\right]$; L: biggest diameter $[\mathrm{mm}] ; \mathrm{W}$ : smallest diameter $[\mathrm{mm}])$. The mice were killed at the eighth week, and the tumors were weighted by scales. Experimental content and animal manipulation protocols were approved by the Medical Ethics Committee of the Huaihe Hospital Henan University.

\section{Statistical analysis}

Nonparametric tests using SPSS program (version 11.5, USA) were performed to analyze data of tumor weight $(\mathrm{n}=6)$. One-way analysis of variance using SPSS program or Student's $t$-test using GraphPad Prism 7 was performed to analyze other experimental data. Data were from three independent experiments (each experiment generated five to six effective results) and were expressed as mean \pm SD. A $P$-value $<0.05$ was considered statistically significant.

\section{Results \\ Inhibition of cell viability by Rhein in three RCC cell lines}

We first examined the cytotoxicity of Rhein in three different RCC cell lines by CCK- 8 assay. A498, 786-O and ACHN cells were, respectively, treated with Rhein at $0,10,20,40$, 80 and $160 \mu \mathrm{M}$ for $48 \mathrm{~h}$. Then cell viability was analyzed. A decreased cell viability following treatment with various concentrations of Rhein in these three cell lines was shown in Figure $1 \mathrm{~A}-\mathrm{C}$. The half-maximal inhibitory concentration $\left(\mathrm{IC}_{50}\right)$ value of Rhein in each cell line is provided in Figure 1D. Among these, we observed that ACHN cells were most sensitive to Rhein treatment with the lowest $\mathrm{IC}_{50}$ value $(56.7 \mu \mathrm{M}), 786-\mathrm{O}$ cells were somewhat resistant $\left(\mathrm{IC}_{50}=58.3 \mu \mathrm{M}\right)$, while $\mathrm{A} 498$ cells were relatively more resistant to Rhein $\left(\mathrm{IC}_{50}=60.8 \mu \mathrm{M}\right)$, all close to $60 \mu \mathrm{M}$.

\section{Rhein-induced time- and dose-dependent antiproliferation of RCC cells}

After the $\mathrm{IC}_{50}$ value for each RCC cell line was determined, we decided to use the $60 \mu \mathrm{M}$ concentration of Rhein to treat the three cell lines and monitored cell proliferation at 0,12 , 24,36 and $48 \mathrm{~h}$ posttreatment by cell counting assay. The results are shown in Figure 2A. We found that all three RCC cell lines treated with a constant dose of Rhein $(60 \mu \mathrm{M})$ showed decreased cell proliferation in a time-dependent manner. By incubation with 0,30 and $60 \mu \mathrm{M}$ of Rhein for $48 \mathrm{~h}$, the colony formation of A498 cells revealed a dose-dependent inhibition of in vitro clonosurvival ability (Figure 2B). To understand more about the antiproliferation activity of Rhein in RCC cells, we applied cell cycle and apoptosis detection assays. Results shown in Figure S1A revealed that $48 \mathrm{~h}$ of $60 \mu \mathrm{M}$ Rhein treatment caused a cell cycle arrest in G1 phase. However, similar treatment did not induce apoptosis of A498 cells (Figure S1B). These results supported that Rhein induced antiproliferation of RCC cells through dysregulation of cell cycle in vitro.

\section{Rhein-induced antimigration and anti- invasion of RCC cells}

To assess whether Rhein affects migration and invasion of RCC cells, we then examined the migration and invasion 

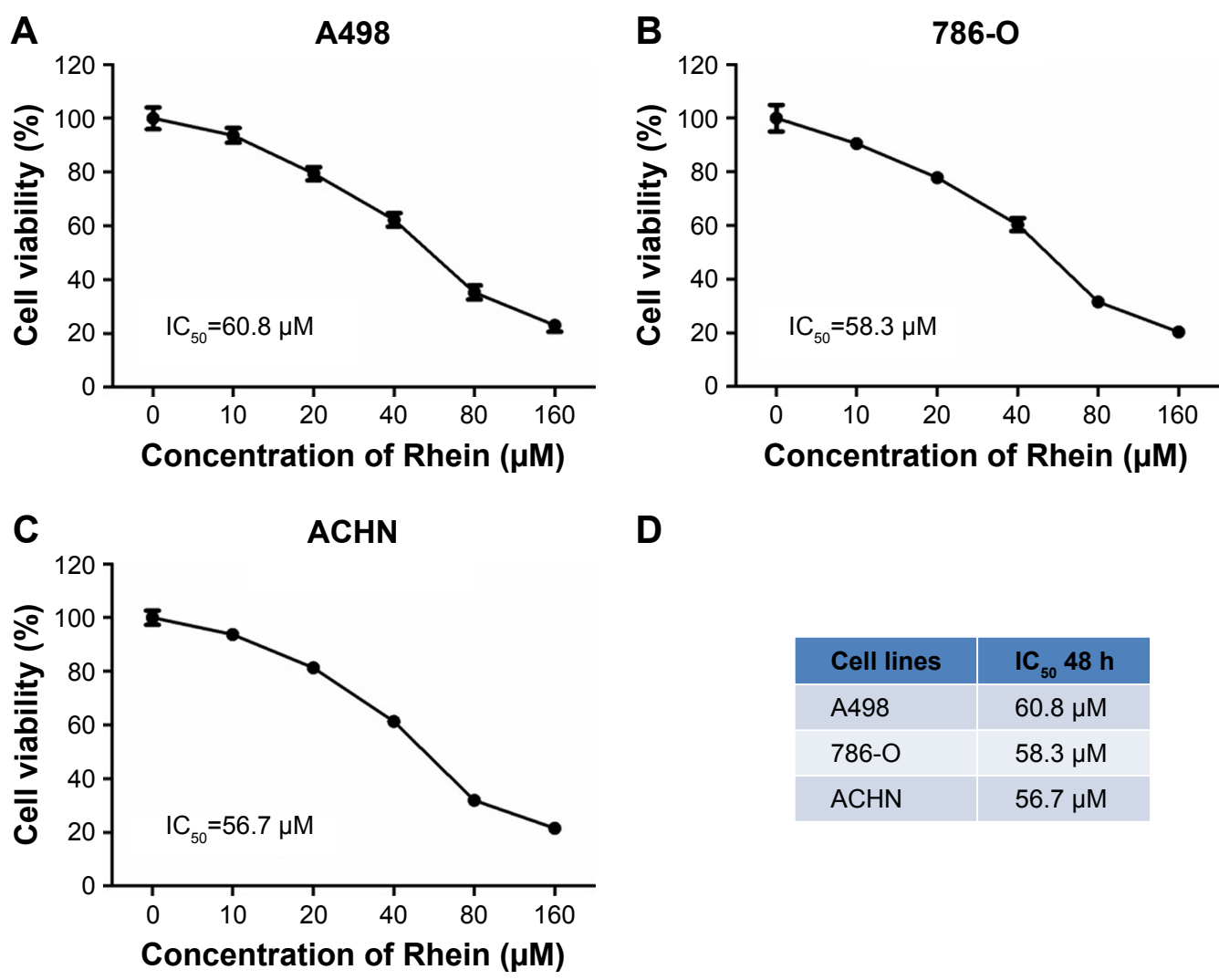

D

\begin{tabular}{|l|l|}
\hline Cell lines & $\mathrm{IC}_{50} \mathbf{4 8} \mathrm{h}$ \\
\hline $\mathrm{A} 498$ & $60.8 \mu \mathrm{M}$ \\
\hline $786-\mathrm{O}$ & $58.3 \mu \mathrm{M}$ \\
\hline $\mathrm{ACHN}$ & $56.7 \mu \mathrm{M}$ \\
\hline
\end{tabular}

Figure I Identification of the $\mathrm{IC}_{50}$ of Rhein in RCC cell lines.

Notes: (A) A498 cells were treated with serial dilution of Rhein $(0,10,20,40,80$ and I60 $\mu \mathrm{M})$ for $48 \mathrm{~h}$. CCK-8 assay was performed as described in the Materials and Methods section. The IC $\mathrm{C}_{50}$ was calculated by SPSS software. (B) The IC $\mathrm{C}_{50}$ of Rhein in 786-O cells was identified as described in (A). (C) The IC ${ }_{50}$ of Rhein in ACHN cells was identified as described in (A). (D) The table showed the summarized data of $I C_{50}$ of Rhein in three RCC cell lines.

Abbreviations: $\mathrm{IC}_{50}$, half-maximal inhibitory concentration; RCC, renal cell carcinoma.

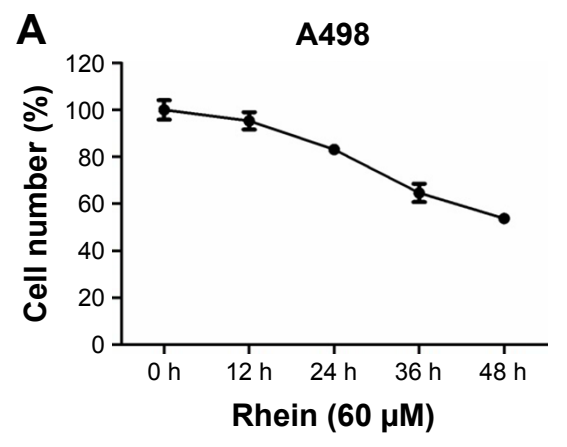

B

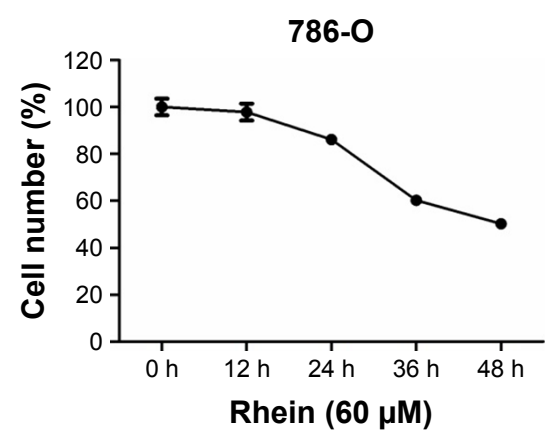

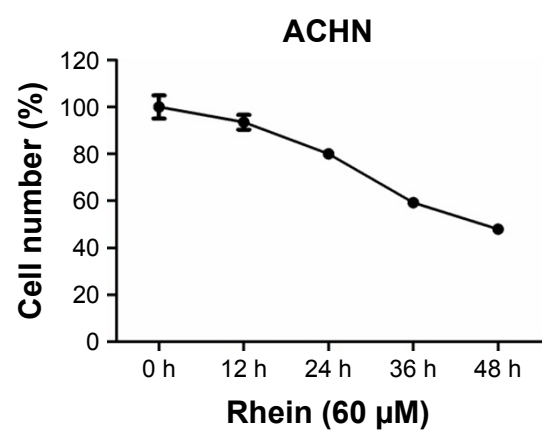

A498

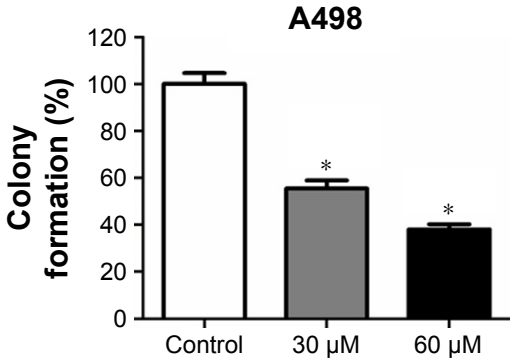

Figure 2 Rhein inhibits the growth activity of RCC cells in vitro.

Notes: (A) Cell number counting assay was performed as described in the Materials and Methods section. Rhein inhibited A498, 786-O and ACHN cell proliferation and growth in vitro at $\mathrm{IC}_{50}$ of $60 \mu \mathrm{M}$. (B) Colony formation assay was performed as described in the Materials and Methods section. A498 cells in a six-well plate were treated with different dilutions of Rhein $(30$ or $60 \mu \mathrm{M})$. The left showed the cell photographs at I4 days. The right panel showed the quantitative results. $* P<0.00$ I.

Abbreviations: $\mathrm{IC}_{50}$, half-maximal inhibitory concentration; RCC, renal cell carcinoma. 
of Rhein-treated RCC cells through wound healing and Transwell assays, respectively. Our in vitro scratch wound healing assay showed an almost complete wound healing in control (nontreated) A498 and 786-O cells in both serum-free and 5\% FBS medium, whereas clear wound in Rhein-treated cells (Figure 3). Similarly, the invasion of A498 and 786-O cells was inhibited by Rhein in a dose-dependent manner with both short-time ( $24 \mathrm{~h}$ ) and long-time ( $48 \mathrm{~h}$ ) incubation (Figure 4). These results suggested that Rhein treatment strongly inhibited the motility of RCC cells in vitro.

\section{Suppression of in vivo RCC tumor growth by Rhein}

To further evaluate the therapeutic efficacy of Rhein for RCC treatment, we performed intraperitoneal administrations in RCC xenografts. 786-O cells were first utilized to do subcutaneous transplantations in nude mice. After tumor formation was accomplished, mice were intraperitoneally administrated with a low dose $(75 \mathrm{mg} / \mathrm{kg})$ or a high dose $(150 \mathrm{mg} / \mathrm{kg})$ of Rhein every 2 days. Mice administered with $100 \mathrm{mg} / \mathrm{kg}$ lysine served as the control group. Two weeks later, mice were
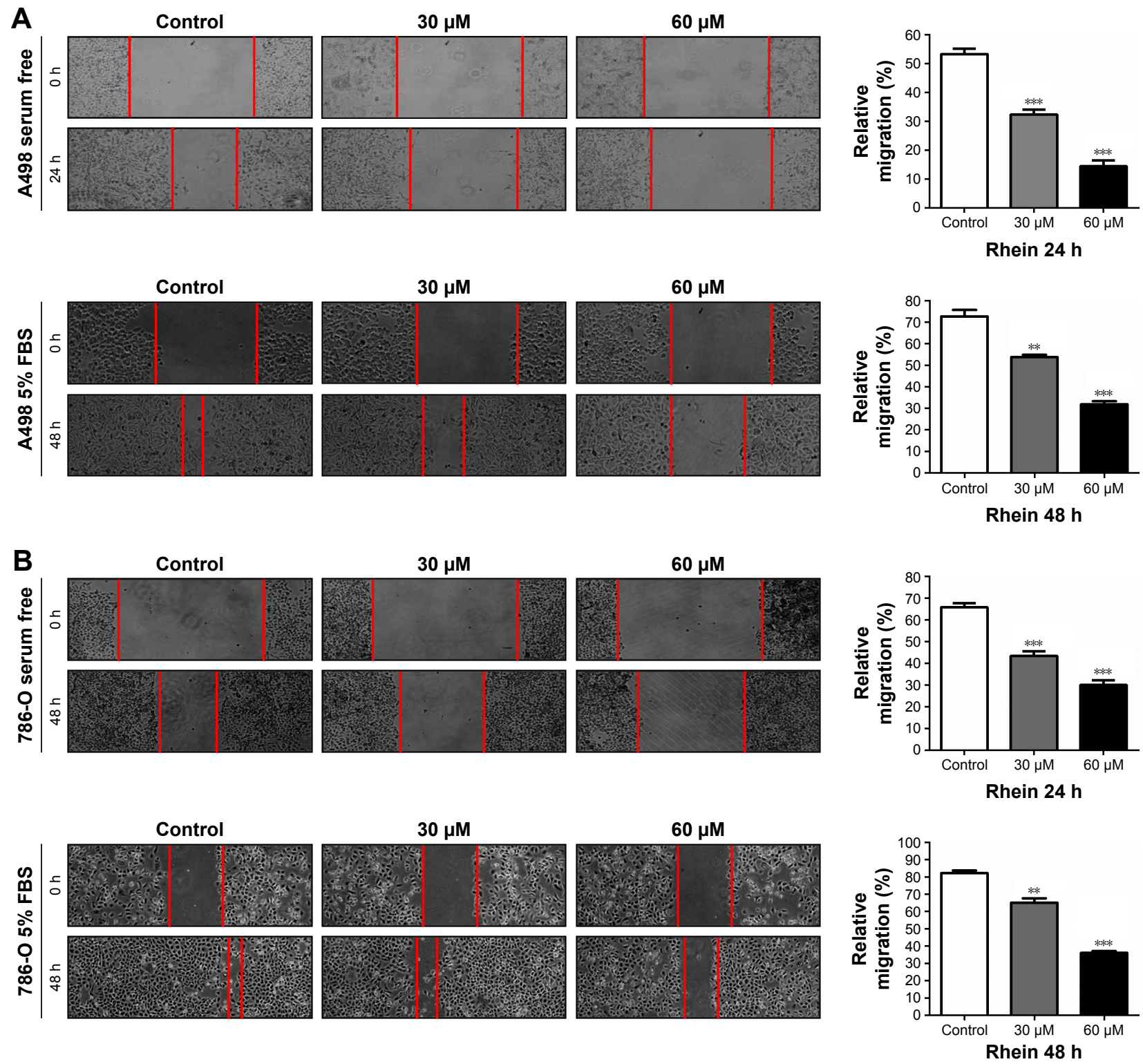

Figure 3 Rhein inhibits the wound healing ability of A498 and 786-O cells in vitro.

Notes: (A) Inhibition of wound healing of A498 cells by Rhein. (B) Inhibition of wound healing of 786-O cells by Rhein. Wound healing assay was performed as described in the Materials and Methods section at $24 \mathrm{~h}$ (serum-free medium) or $48 \mathrm{~h}$ (5\% FBS medium). The left panel indicated photographs of relative wound healing that was monitored by using light microscope. The right panel showed the quantitative results. Relative wound healing was determined by measuring the width of the wounds on photographic images by microruler. The values presented are the mean \pm SD from three independent experiments. Magnification $\times 40$. $* * P<0.0 \mathrm{I}$. $* * * P<0.00 \mathrm{I}$.

Abbreviation: FBS, fetal bovine serum. 
A
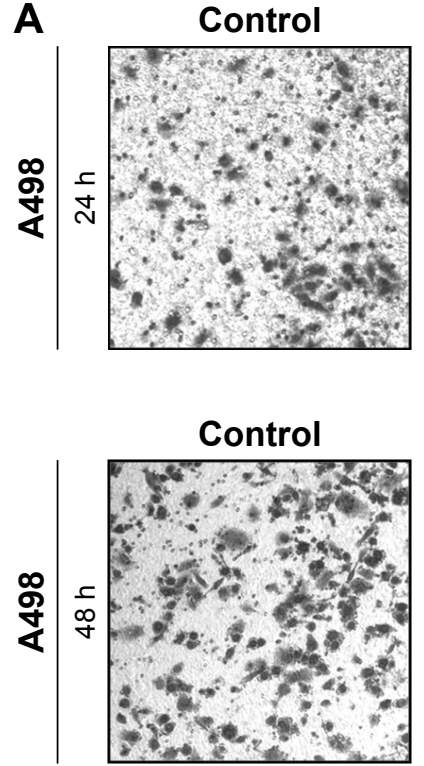

B
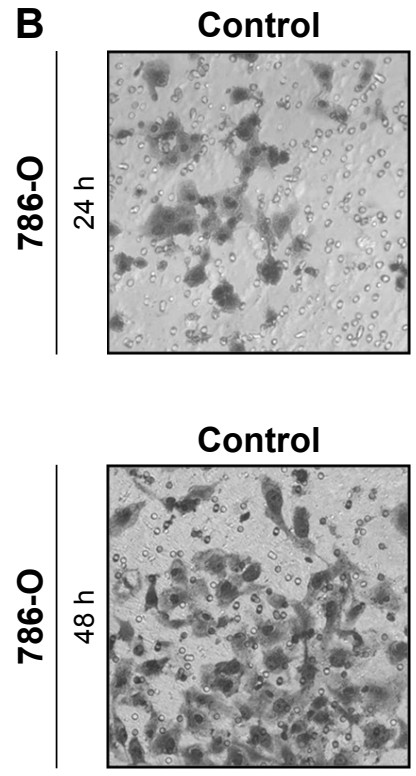

$30 \mu \mathrm{M}$

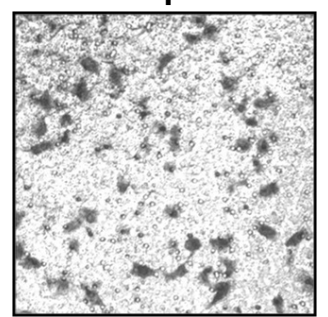

$30 \mu \mathrm{M}$

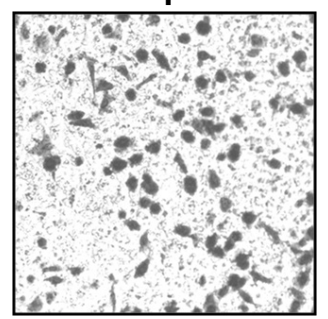

$30 \mu \mathrm{M}$

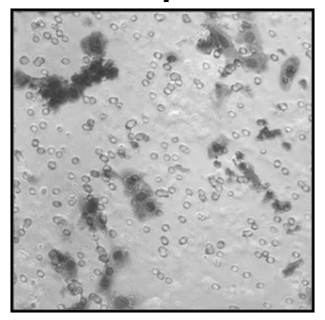

$30 \mu \mathrm{M}$

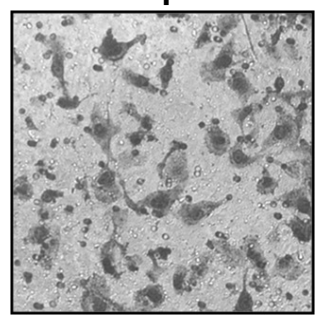

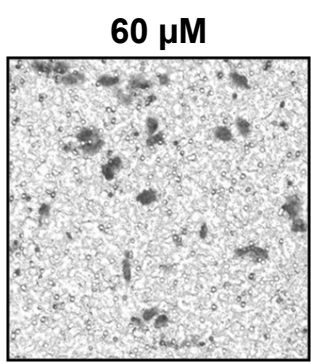

$60 \mu \mathrm{M}$

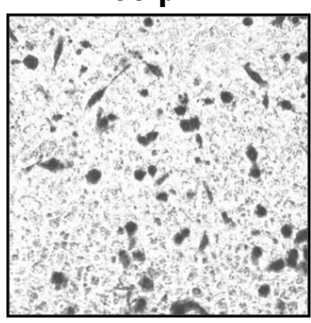

$60 \mu \mathrm{M}$

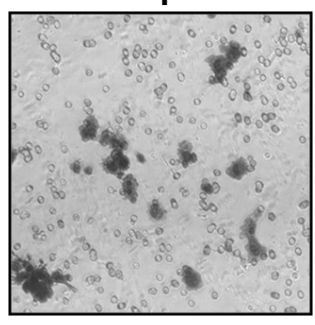

$60 \mu \mathrm{M}$

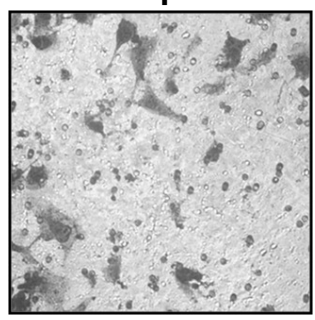

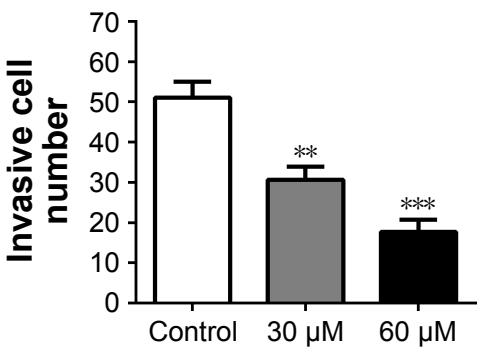

Rhein $24 \mathrm{~h}$

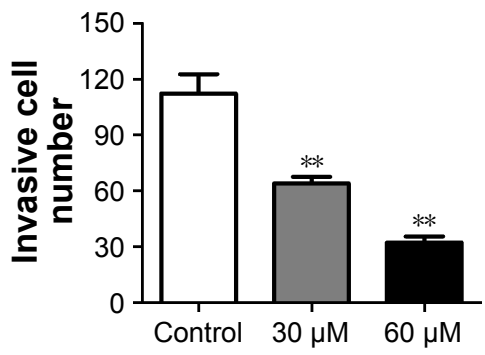

Rhein $48 \mathrm{~h}$

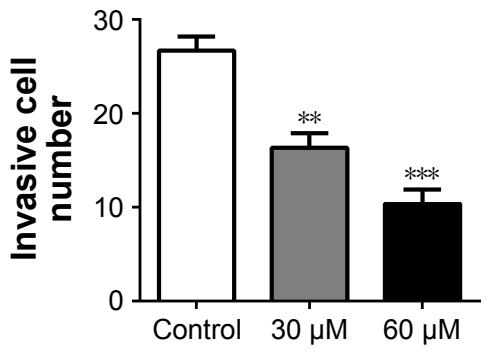

Rhein $24 \mathrm{~h}$

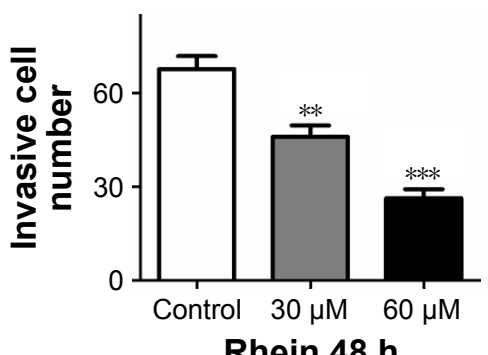

Figure 4 Rhein inhibits the invasive activity of $A 498$ and $786-O$ cells in vitro.

Notes: (A) Effect of Rhein on the invasive activity of A498 cells in vitro. (B) Effect of Rhein on the invasive activity of 786-O cells in vitro. Cells were seeded onto a Matrigel chamber in the absence or presence of Rhein (30 or $60 \mu \mathrm{M})$. Transwell invasion assays were performed as described in the Materials and Methods section at 24 or $48 \mathrm{~h}$ after treatment. The left panel showed the number of invaded cells, which was photographed by a microscope. The right panel showed the quantitative results. The values presented are the mean \pm SD from three independent experiments. Magnification $\times 100$. $* * P<0.01$. $* * * P<0.001$.

killed and tumors were stripped and weighed. The results showed that compared to the control tumors, Rhein was able to inhibit tumor growth in nude mice, reflecting by smaller size and lighter weight (Figure 5).

\section{Antitumor effects of Rhein were associated with the inhibition of MAPK/NF- $\kappa B$ signaling}

To explore the molecular mechanism of antitumor action of Rhein, we investigated the effect of Rhein on two cancer-related signaling pathways: mitogen-activated protein kinase (MAPK) and nuclear factor kappa-light-chain enhancer of activated B cells (NF-KB). MAPK is a chain of proteins in the cell that communicate a signal from a membrane receptor of the cell to the DNA in the nucleus of the cell. NF- $\kappa \mathrm{B}$ is a protein complex that controls transcription of DNA, cytokine production and cell survival. Aberrant regulation of MAPK and NF- $\kappa B$ has been linked to cancer. As shown in Figure 6, Western blot analysis revealed that Rhein treatment (24-48 h) inhibited the phosphorylation 

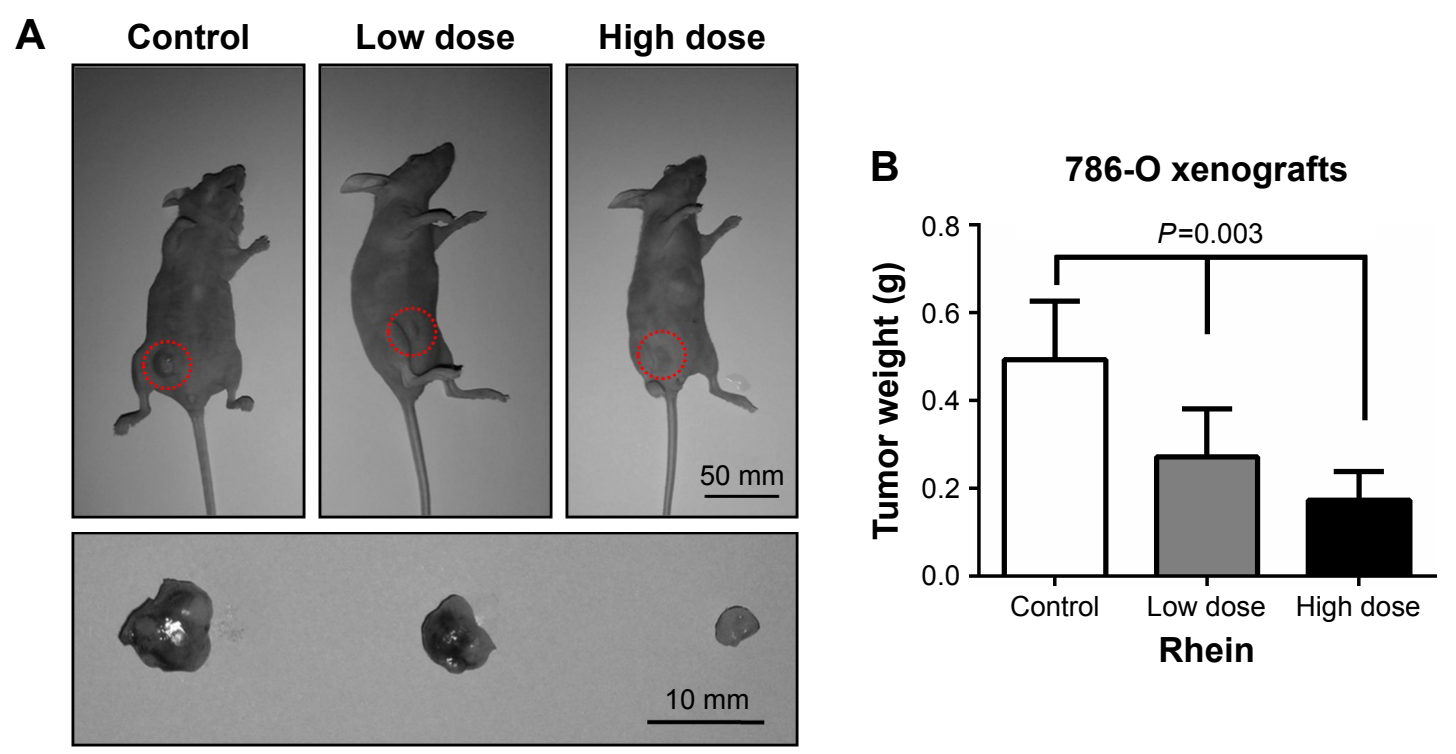

Figure 5 Rhein $(75$ and $150 \mathrm{mg} / \mathrm{kg}$ ) exhibits the antitumor activity in 786-O xenograft tumor models.

Notes: (A) The rate of tumor growth and tumor size were significantly reduced by different doses of Rhein (75 and I50 mg/kg). (B) The tumor weights were significantly decreased by different doses of Rhein (75 and $150 \mathrm{mg} / \mathrm{kg})$.

of extracellular signal-regulated kinase (ERK) and c-Jun $\mathrm{N}$-terminal kinase (JNK; two main components of MAPKs), phosphorylation of Akt and expression of two NF- $\mathrm{KB}$ targets, MMP9 and CCND1 in a dose-dependent manner in both
A498 and 789-O cells. However, short-time (15-30 min) treatment barely impacted on phosphorylation of the three kinases: ERK, JNK and Akt (Figure S2). These findings suggested that long-time (hours) Rhein treatment might exert

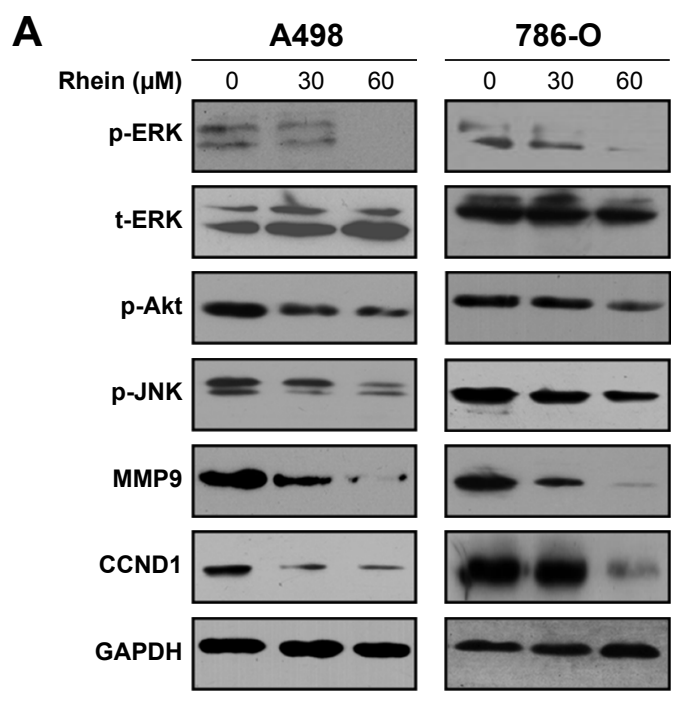

B
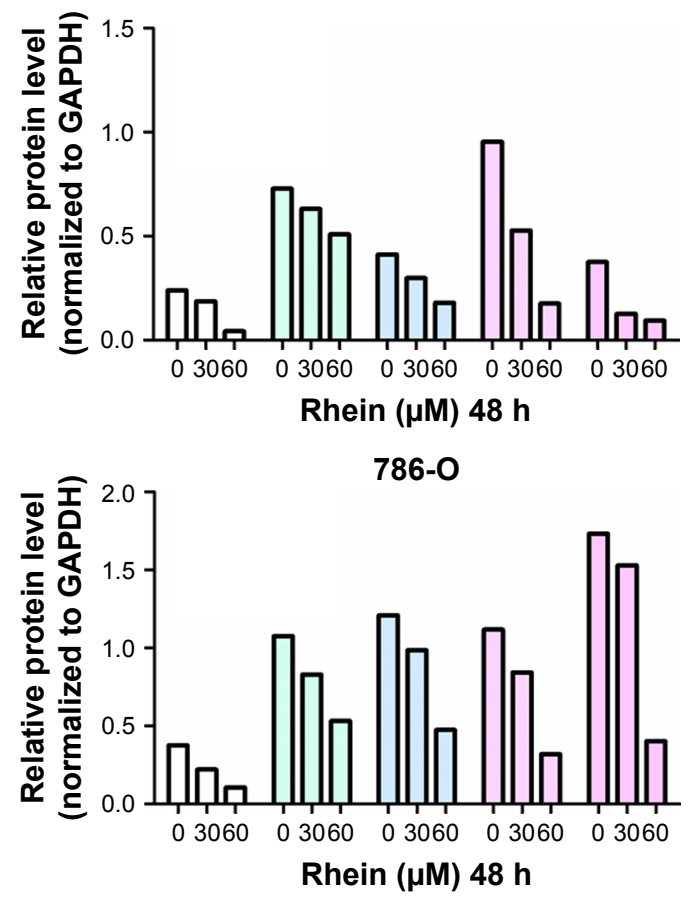

p-ERK $\square$ p-Akt $\square$ p-JNK $\square$ MMP9 $\square$ CCND1

Figure 6 The key signaling pathways regulating proliferation and metastasis are suppressed during Rhein treatment.

Notes: (A) 30 or $60 \mu \mathrm{M}$ Rhein inhibited the expression of p-ERK, p-Akt, MMP9 and CCNDI in A498 and 786-O cells at 48 h. (B) The quantitative results of the key molecules changing showed in (A) by ImageJ software.

Abbreviations: GAPDH, glyceraldehyde 3-phosphate dehydrogenase; MMP9, matrix metalloproteinase 9; p-JNK, phospho-c-Jun N-terminal kinase; p-ERK, phosphoextracellular signal-regulated kinase. 
antitumor effects by inhibiting the activation of MAPK/ $\mathrm{NF}-\kappa \mathrm{B}$ signaling pathways.

\section{Discussion}

Chinese herb medicine has been served for therapies of a wide range of human diseases, including diabetes, cancers and cardiovascular diseases. ${ }^{10}$ Recently, a large body of academic reports have demonstrated the antitumor activities of some Chinese herb medicine in leukemia, gastric cancer and prostate cancer. ${ }^{22-24}$ Hence, it is an alternative choice to treat human cancers, especially for those who are resistant to typical cancer therapies. In the present study, we centered on the biologic effects of Rhein in RCC and identified its antitumor activities by influencing cell proliferation, migration and invasion. The most important finding is that Rhein could also inhibit tumor growth in nude mice by intraperitoneal administration in vivo. Mechanistically, we verified that MAPK (ERK and JNK) phosphorylation and NF- $\kappa$ B activation might be the linkage mediating the tumor-suppressing functions of Rhein in RCC cells.

Although it remains unclear about the effects of Rhein in RCC cells, we might speculate from the studies of Rhein in several other cancers. As a major bioactive constituent of the rhizome of rhubarb, Rhein has various pharmacologic effects, including antifibrosis, antioxidant, anti-inflammatory and antimicrobial activities. ${ }^{25}$ Additionally, Rhein exerts its antitumor effects via the modulation of processes of cell proliferation, apoptosis, migration and invasion. ${ }^{26}$ Our findings are also consistent with these previous conclusions: Rhein exerts antitumor effects in RCC cells, both in vitro and in vivo. Moreover, we observed that Rhein significantly inhibited RCC cell migration and invasion, two pivotal steps toward cancer metastasis. As is known, RCC is one of the most lethal malignancies in the urologic system because of its high incidence of metastasis. ${ }^{6}$ For this point, our findings suggested that Rhein may be a useful candidate agent to prevent RCC progression and metastasis. For the potential clinical applications of Rhein, we used up to $60 \mu \mathrm{M}$ Rhein to induce RCC cell cycle arrest, proliferation inhibition and migration/invasion repression in vitro. This concentration is relatively low but within the range used by other researchers (30-180 $\mu \mathrm{M})$. The wide range of Rhein concentrations might be due to the different tolerance of cells. We speculated that RCC cells are somewhat sensitive to Rhein, because the $\mathrm{IC}_{50}$ values $(48 \mathrm{~h})$ of three RCC cell lines are all close to $60 \mu \mathrm{M}$. In our study, mice burdened with xenografts were intraperitoneally administrated with a low dose $(75 \mathrm{mg} / \mathrm{kg})$ or a high dose $(150 \mathrm{mg} / \mathrm{kg})$ of Rhein. We observed that Rhein was able to inhibit tumor growth in nude mice, but failed to detect other tissue toxicities because of restricted conditions. We believe that excessive dose of Rhein harms healthy digestive system and liver, but the direct evidence is lacking now. The bioavailability of Rhein is a key determinant of its effectiveness in vivo. Although the mice plasma concentration of Rhein was absent from our study, further phamacokinetic study in rat model will provide more details, and our in vitro concentrations of Rhein used on RCC cells may have in vivo relevance. Rhein has long been used as a traditional Chinese medicine, but so far the minimal effective plasma concentration in human is unknown. Our results, together with data reported by others, will provide a clinical reference for the Rhein dose in treating RCC patients.

Our study revealed that Rhein exerted antitumor effects in RCC cells by inactivation of MAPK/NF- $\kappa \mathrm{B}$ signaling pathways. Two earlier studies have demonstrated that Rhein inhibited tumorigenesis through restraining MAPK phosphorylation. ${ }^{27,28}$ In our study, ERK, JNK, Akt phosphorylation and NF- $\kappa \mathrm{B}$ activation were found to be inhibited by Rhein treatment, indicating that Rhein could inhibit MAPK/ $\mathrm{NF}-\kappa \mathrm{B}$ signaling pathways in RCC cells.

However, our present study has several limitations. Although we confirmed that MAPK/NF- $\kappa B$ signaling pathway was associated with the essential role of Rhein in inhibiting RCC cell proliferation, migration and invasion, the direct evidence was absent. The application of pathway inhibitors or agonists might explain more about this question. On the other hand, we did not establish an in vivo RCC metastasis model to confirm our in vitro results. Further investigations are imperative to resolve these issues.

\section{Conclusion}

In summary, our results showed that Rhein treatment significantly inhibits malignant phenotypes of RCC cells through modulation of cell proliferation, migration and invasion. And its tumor-suppressing activity is associated with repressed MAPK/NF- $\kappa$ B signaling. Therefore, Rhein might be a powerful therapeutic agent for RCC treatment.

\section{Acknowledgment}

This work was supported by scientific and technology project of Henan Province (No 182102310267).

\section{Disclosure}

The authors report no conflicts of interest in this work. 


\section{References}

1. Compérat E, Camparo P. Histological classification of malignant renal tumours at a time of major diagnostic and therapeutic changes. Diagn Interv Imaging. 2012;93:221-231.

2. De P, Otterstatter MC, Semenciw R, Ellison LF, Marrett LD, Dryer D. Trends in incidence, mortality, and survival for kidney cancer in Canada, 1986-2007. Cancer Causes Control. 2014;25:1271-1281.

3. Pavlovich CP, Schmidt LS. Searching for the hereditary causes of renalcell carcinoma. Nat Rev Cancer. 2004;4:381-393.

4. Pantuck AJ, Zisman A, Belldegrun AS. The changing natural history of renal cell carcinoma. J Urol. 2001;166:1611-1623.

5. Cheville JC, Lohse CM, Zincke H, Weaver AL, Blute ML. Comparisons of outcome and prognostic features among histologic subtypes of renal cell carcinoma. Am J Surg Pathol. 2003;27:612-624.

6. Cohen HT, McGovern FJ. Renal-cell carcinoma. N Engl J Med. 2005; 353:2477-2490

7. Duensing S, Hohenfellner M. Adjuvant therapy for renal-cell carcinoma: settled for now. Lancet. 2016;387:1973-1974.

8. Zhang Y, Liu W, He W, et al. Tetrandrine reverses epithelial-mesenchymal transition in bladder cancer by downregulating Gli-1. Int J Oncol. 2016;48:2035-2042.

9. Kumar A, Kumar Singh U, Chaudhary A. Honokiol analogs: a novel class of anticancer agents targeting cell signaling pathways and other bioactivities. Future Med Chem. 2013;5:809-829.

10. Markman M. Safety issues in using complementary and alternative medicine. J Clin Oncol. 2002;20:39S-41S.

11. Cui Y, Shu XO, Gao Y, et al. Use of complementary and alternative medicine by Chinese women with breast cancer. Breast Cancer Res Treat. 2004;85:263-270.

12. Richardson MA, Sanders T, Palmer JL, et al. Complementary/alternative medicine use in a comprehensive cancer center and the implications for oncology. J Clin Oncol. 2000;18:2505-2514.

13. Huang Q, Lu G, Shen HM, Chung MC, Ong CN. Anti-cancer properties of anthraquinones from rhubarb. Med Res Rev. 2007;27:609-630.

14. Lin S, Li JJ, Fujii M, Hou DX. Rhein inhibits TPA-induced activator protein-1 activation and cell transformation by blocking the JNKdependent pathway. Int J Oncol. 2003;22:829-833.

15. Lin YJ, Zhen YS. Rhein lysinate suppresses the growth of breast cancer cells and potentiates the inhibitory effect of Taxol in athymic mice. Anticancer Drugs. 2009;20:65-72.
16. Liu J, Zhang K, Zhen YZ, et al. Antitumor activity of rhein lysinate against human glioma U87 cells in vitro and in vivo. Oncol Rep. 2016; 35:1711-1717.

17. Cichewicz RH, Zhang Y, Seeram NP, Nair MG. Inhibition of human tumor cell proliferation by novel anthraquinones from daylilies. Life Sci. 2004;74:1791-1799.

18. Shi P, Huang Z, Chen G. Rhein induces apoptosis and cell cycle arrest in human hepatocellular carcinoma BEL-7402 cells. Am J Chin Med. 2008;36:805-813.

19. Li Y, Xu Y, Lei B, Wang W, Ge X, Li J. Rhein induces apoptosis of human gastric cancer SGC-7901 cells via an intrinsic mitochondrial pathway. Braz J Med Biol Res. 2012;45:1052-1059.

20. Miccadei S, Pulselli R, Floridi A. Effect of lonidamine and rhein on the phosphorylation potential generated by respiring rat liver mitochondria. Anticancer Res. 1993;13:1507-1510.

21. Mukherjee S, Roy M, Dey S, Bhattacharya RK. A mechanistic approach for modulation of arsenic toxicity in human lymphocytes by curcumin, an active constituent of medicinal herb curcuma longa linn. J Clin Biochem Nutr. 2007;41(1):32-42.

22. Cha YY, Lee EO, Lee HJ, et al. Methylene chloride fraction of Scutellaria barbata induces apoptosis in human U937 leukemia cells via the mitochondrial signaling pathway. Clin Chim Acta. 2004;348:41-48.

23. Ma J, Fu NY, Pang DB, Wu WY, Xu AL. Apoptosis induced by isoliquiritigenin in human gastric cancer MGC-803 cells. Planta Med. 2001;67:754-757.

24. Hsieh TC, Lu X, Guo J, et al. Effects of herbal preparation Equiguard on hormone-responsive and hormone-refractory prostate carcinoma cells: mechanistic studies. Int J Oncol. 2002;20:681-689.

25. Zhou YX, Xia W, Yue W, et al. Rhein: a review of pharmacological activities. Evid Based Complement Alternat Med. 2015;2015:578107.

26. Huang Q, Lu G, Shen HM, Chung MC, Ong CN. Anti-cancer properties of anthraquinones from rhubarb. Med Res Rev. 2007;27:609-630.

27. Chen YY, Chiang SY, Lin JG, et al. Emodin, aloe-emodin and rhein inhibit migration and invasion in human tongue cancer SCC-4 cells through the inhibition of gene expression of matrix metalloproteinase-9. Int J Oncol. 2010;36:1113-1120.

28. Zhou G, Peng F, Zhong Y, Chen Y, Tang M, Li D. Rhein suppresses matrix metalloproteinase production by regulating the Rac1/ROS/ MAPK/AP-1 pathway in human ovarian carcinoma cells. Int J Oncol. 2017;50:933-941. 


\section{Supplementary materials}

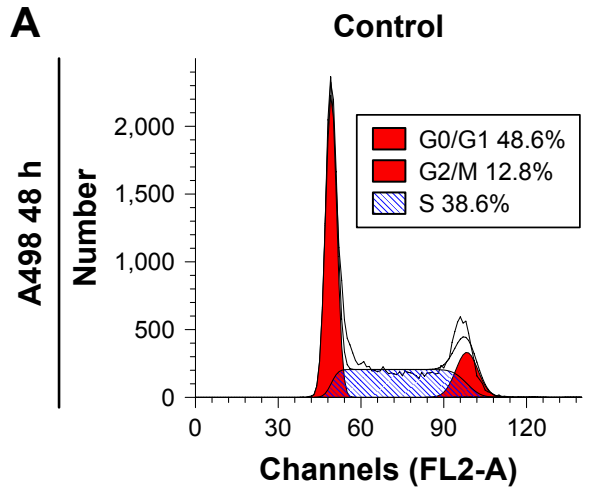

B

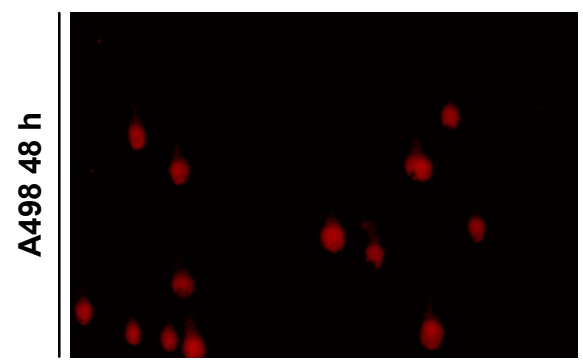

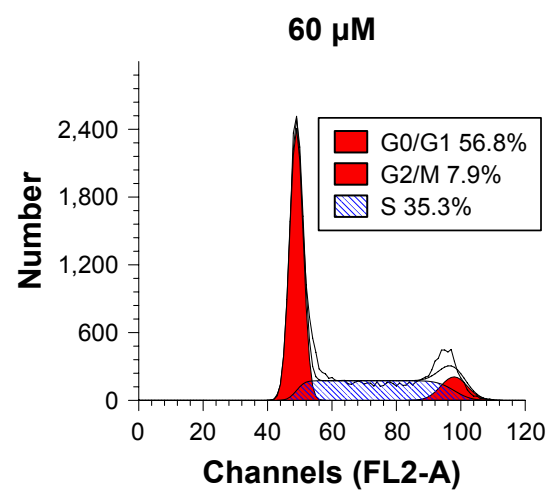
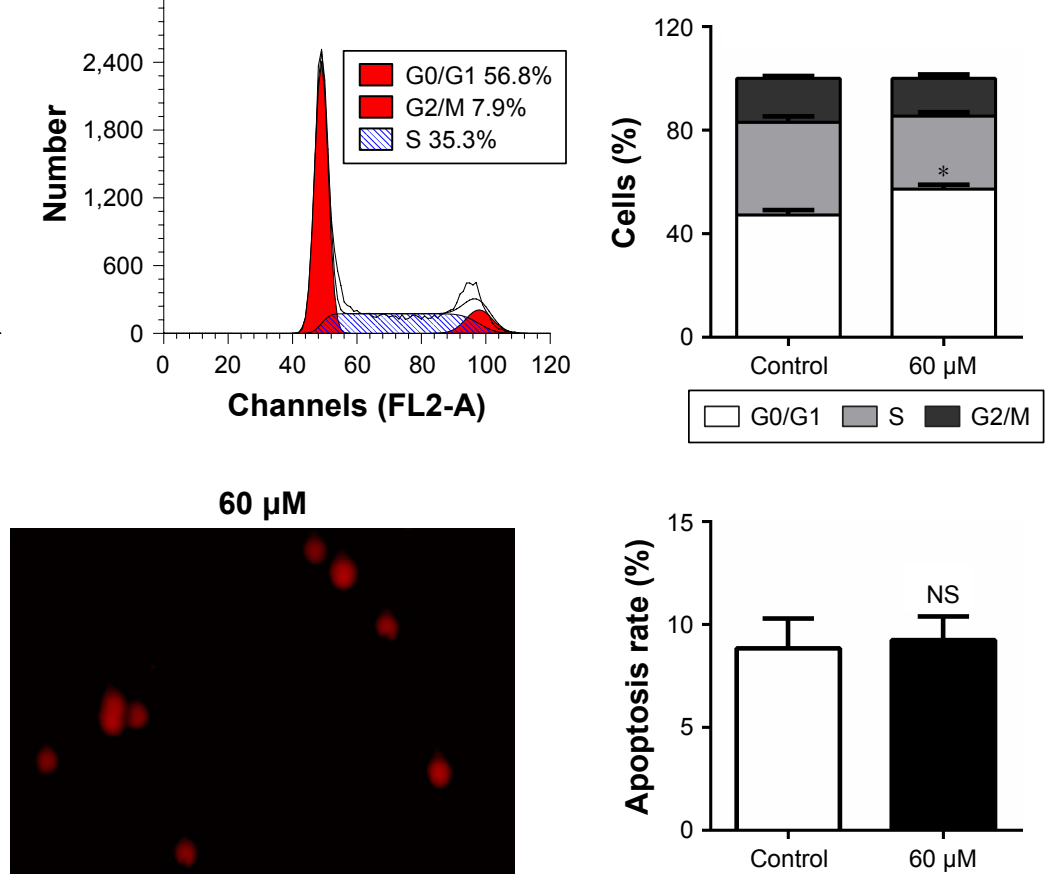

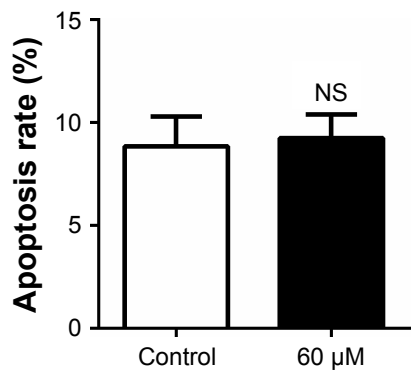

Rhein $48 \mathrm{~h}$

Figure SI Rhein induces a GI cell cycle arrest in A498 cells in vitro.

Notes: (A) A498 cells were treated with $60 \mu \mathrm{M}$ Rhein for $48 \mathrm{~h}$. After that, the cells were harvested for cell cycle assay. The left panel depicts DNA content, while the right shows the quantitative results. (B) SCGE analysis of cell apoptosis. Apoptotic cells were characterized by pyknotic nuclei and long comet tails stretching toward the same direction. Treatment of $60 \mu \mathrm{M}$ Rhein for $48 \mathrm{~h}$ did not increase the apoptotic levels of A498 cells. The right panel shows the quantitative results. $* P<0.05$. Abbreviations: SCGE, single-cell gel electrophoresis; NS, not significant.

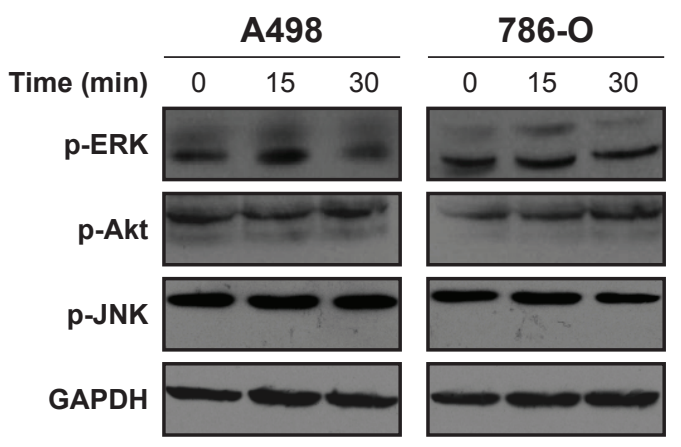

Figure S2 The key signaling pathways regulating proliferation and metastasis are not suppressed during short-time Rhein treatment. Note: $60 \mu \mathrm{M}$ Rhein did not inhibit the expression of p-ERK, p-Akt and p-JNK in A498 and 786-O cells at 15 or $30 \mathrm{~min}$.

Abbreviations: GAPDH, glyceraldehyde 3-phosphate dehydrogenase; p-JNK, phospho-c-Jun N-terminal kinase; p-ERK, phospho-extracellular signal-regulated kinase.

OncoTargets and Therapy

\section{Publish your work in this journal}

OncoTargets and Therapy is an international, peer-reviewed, open access journal focusing on the pathological basis of all cancers, potential targets for therapy and treatment protocols employed to improve the management of cancer patients. The journal also focuses on the impact of management programs and new therapeutic agents and protocols on

\section{Dovepress}

patient perspectives such as quality of life, adherence and satisfaction. The manuscript management system is completely online and includes a very quick and fair peer-review system, which is all easy to use. Visit http://www.dovepress.com/testimonials.php to read real quotes from published authors. 